\title{
THE PHYSIOLOGICAL RESPONSE OF ATHLETES WITH IMPAIRMENTS IN WHEELCHAIR BASKETBALL GAME
}

original paper

( ) University School of Physical Education in Wroclaw

DOI: https://doi.org/10.5114/hm.2019.84005

\section{JOLANTA MARSZALEK ${ }^{1}$, KAROL GRYKO ${ }^{2}$, GRZEGORZ PROKOPOWICZ ${ }^{1}$, ANDRZEJ KOSMOL ${ }^{1}$, ANNA MROZ ${ }^{2}$, NATALIA MORGULEC-ADAMOWICZ ${ }^{1}$, BARTOSZ MOLIK ${ }^{1}$ \\ ${ }^{1}$ Faculty of Rehabilitation, Józef Piłsudski University of Physical Education in Warsaw, Warsaw, Poland \\ ${ }^{2}$ Faculty of Physical Education, Józef Piłsudski University of Physical Education in Warsaw, Warsaw, Poland}

\begin{abstract}
Purpose. The aim of the study was to analyse the physiological response of wheelchair basketball (WB) athletes related to type of impairment and functional classification in game situations.

Methods. Overall, 15 male players from the Polish National Wheelchair Basketball Team were observed during friendly and championships games (2017 and 2018). Heart rate (peak and average: $\mathrm{HR}_{\text {peak }}, \mathrm{HR}_{\mathrm{av}}$ ) and the number of sprints were monitored for each player per a full game with Polar Team Pro. For each athlete, 5 HR zones were calculated based on peak oxygen uptake, anaerobic threshold, $\mathrm{HR}_{\text {peak }}$, body weight, and age (aerobic laboratory test). Heart rate reserve (HRR) and percentage of HRR (\%HRR) were established. Results were compared between athletes related to the type of impairment (spinal cord injuries and other physical impairments) and functional classification (group A: 1.0-2.5 points; group B: 3.0-4.5 points).
\end{abstract}

Results. The results showed the specificity of WB games, i.e. all players were found in all HR zones with different contribution. Group A athletes played less than those form group B in the $5^{\text {th }} H R$ zone ( $15 \%$ and $21 \%$, respectively), had significantly lower $\mathrm{HR}_{\text {peak }}, \mathrm{HR}_{\mathrm{a}}, \mathrm{HRR}, \% \mathrm{HRR}$, and did more sprints.

Conclusions. The study confirmed a differential specificity of a WB game. Significant differences were observed in the physiological response between WB athletes representing different functional levels. This knowledge is important to plan preseason conditioning exercises for individual WB athletes. Further studies are needed to better understand the physiological response of WB players.

Key words: adapted physical activity, game performance, heart rate, impairment, sport

\section{Introduction}

Wheelchair basketball (WB) a is popular and wellknown sports discipline for people with impairments. The importance of WB for athletes in their daily lives was strongly underlined in the literature [1]. WB is a Paralympic team sport for individuals with physical impairments characterized by chronically disabling conditions which result in loss of use of the legs, e.g. spinal cord injury, cerebral palsy, musculoskeletal conditions, spina bifida, amputation, poliomyelitis, and others, which reduce the ability to play running bas- ketball as an able-bodied player [2-4]. On the basis of the criteria of functional abilities, all athletes are divided into 5 classes (functional classification 1.0, 2.0, 3.0, 4.0, and 4.5 points). The International Wheelchair Basketball Federation (IWBF) also mandates 3 subclasses (functional classification 1.5, 2.5, and 3.5 points) for athletes presenting mixed characteristics of 2 classes (functional classification 1.0 and 2.0, 2.0 and 3.0, or 3.0 and 4.0) [2,3]. Moreover, the classification guide assigns athletes without pelvic control (functional classification 1.0-2.5 points) into group $\mathrm{A}$ and those with pelvic control (functional classifica-

Correspondence address: Jolanta Marszałek, Faculty of Rehabilitation, Józef Piłsudski University of Physical Education in Warsaw, ul. Marymoncka 34, 00-968 Warsaw, Poland, e-mail: marszalek.jolanta@gmail.com

Received: November 13, 2018

Accepted for publication: March 20, 2019

Citation: Marszalek J, Gryko K, Prokopowicz G, Kosmol A, Mroz A, Morgulec-Adamowicz N, Molik B. The physiological response of athletes with impairments in wheelchair basketball game. Hum Mov. 2019;20(4):1-7; doi: https://doi.org/10.5114/ hm.2019.84005. 
tion 1.0-2.5 points) into group B [2]. The greater the class (points), the higher the functional level of the athlete. In the current IWBF rules for international games, the point limit for the 5 players from one team on the floor at any one time is 14 points (i.e. 1.0 point +2.0 points +3.0 points +3.5 points +4.5 points $=$ 14.0 points) $[2,3]$.

WB has been described as a dynamic and intermittent team game where a team's success depends on the technical, tactical, and physical preparation of the athletes [5]. Players push, stop, and manoeuver the wheelchairs, dribble and pass the ball, shoot, cooperate with teammates, as well as resist the opponents' movements in offensive and defensive parts of the game. Researchers analyse all of these elements to understand which specific factors of the game influence and determine the outcome of the game, and to better recognize players' physiological responses in authentic conditions related to their specific disability and functional classification. For example, Pérez et al. [6] checked physiological exigency in WB through heart rate (HR) monitoring during a competition (7 matches) and established the individual physiological response to game situations, tactical situations, and player's functional classification among two WB athletes. The authors concluded that offensive situations with the ball were the most demanding during the game, and they underlined that a WB game had intermittent physiological demands on the players. They strongly recommended continuation of this type of research because of the small number of subjects in their study.

Pérez et al. [7] expanded the previous study [6] to more subjects and observed more matches (5 WB athletes in 11 matches). The authors monitored the athletes' HR to determine if the training plan was sufficient and they established that there were differences between group A (functional classification 1.0-2.5 points) and group B (functional classification 3.0-4.5 points) in HR reserve (HRR), match periods, and role distribution during a game [7].

Owing to the scarcity of papers concerning WB athletes' physiological response during a game, the authors of the present study decided to extend Pérez et al.'s studies. The aim of this study was to analyse the physiological response of WB athletes in game situations across individual HR zones and the number of sprints in relation to functional classification and disability type. This knowledge will help trainers and athletes to prepare appropriate training plans and to enable athletes to play at the highest level of their abilities.

\section{Material and methods}

\section{Participants}

A total of 15 male WB players representing the Polish National Wheelchair Basketball Team were observed. The athletes were divided into 2 groups, i.e. group A (functional classification 1.0-2.5 points; $n=7$ ) and group B (functional classification 3.0-4.5 points; $n=8$ ). There were no significant differences in age, body weight, or body height between the groups (Table 1).

The researchers observed the athletes during 3 different tournaments: one friendly tournament before the European Championships in Wałbrzych (Poland) in June 2017, the European Championships in Tenerife (Spain) in June 2017, and one friendly tournament in Wałbrzych (Poland) in July 2018. To be included in the analyses, a player had to participate in a minimum 30 minutes of active play in a match [8]. The players were observed and their physiological responses from 15 total games were analysed.

\section{Match monitoring}

HR parameters: peak $\mathrm{HR}\left(\mathrm{HR}_{\text {peak }}\right)$, average $\mathrm{HR}\left(\mathrm{HR}_{\mathrm{av}}\right)$, and $\% \mathrm{HR}_{\mathrm{av}}$, as well as the number of sprints were monitored during each match by using a downloadable wireless Polar Team Pro (Polar Team Pro, Kempele, Finland). The HR parameters were frequencycoded at 1-second registration intervals. All athletes wore a numbered HR chest strap during each match. All data files were downloaded to a computer after each match. Inactive time (e.g. half-time break, timeouts in each match) was also registered by the Polar Team Pro.

\section{Match data analysis}

To establish $\mathrm{HR}_{\text {peak }}$ for each player, aerobic performance laboratory testing was carried out on an arm crank ergometer (Lode ACE, Groningen, the Netherlands) 1-4 weeks before the match (May 2017 and May 2018). This protocol was proposed by Molik et al. [9]. To maximize trunk stability, the athletes used their own basketball wheelchairs and their strapping system (like during the game). The ACE was firmly affixed to a wall-mounted gymnastic ladder. The ergometer's rotation axis was set up on the athlete's glenohumeral joints level. Two assistants stabilized the athlete's wheelchair to minimize rotational movements during arm cranking. The resisting force in the test was systematically increased from 35 watts 
every 2 minutes by 35 watts. The participants tried to keep the speed level of $70 \mathrm{rpm}$. $\mathrm{HR}_{\text {peak }}$, peak oxygen uptake, minute ventilation, and anaerobic threshold were collected. All physiological parameters were measured with the K5 system (Cosmed, Rome, Italy), consisting of a mask and a portable unit worn on the participant's back, and with a Garmin sensor, connected and compatible with K5. Breath-by-breath data were averaged over 10 seconds. Lactate concentration and drop in lactate concentration were determined before the first and the second test, during tests every 2 minutes, as well as directly after the completion of the tests and in the $3^{\text {rd }}, 6^{\text {th }}, 9^{\text {th }}$, and $30^{\text {th }}$ minutes after the test to assess the anaerobic threshold.

A total of 5 HR zones (I: 50-59\%, II: 60-69\%, III: 70-79\%, IV: $80-89 \%$, and V: $90-100 \%)$ were indicated by the Polar Team Pro software. Polar Team Pro counts sprints if acceleration of movement is established. To establish acceleration, the uniformly accelerated motion equation was used. Time $(t)$, velocity $(v)$, and displacement (s) to calculate the uniformly accelerated motion were taken from 3-meter and 5-meter sprint tests. The players had performed these tests before the study, and the average acceleration was set up as $1.5 \mathrm{~m} / \mathrm{s}^{2}$. On the basis of acceleration, the number of sprints was measured during a match by a Polar Team Pro sensor (Polar's algorithm) that was placed on the chest strap (this is the same sensor that measures HR).

Additionally, HRR and percentage of $\mathrm{HRR}$ (\%HRR) were calculated. HRR is the difference between maximum $\mathrm{HR}$ in a game $\left(\mathrm{HR}_{\text {peak }}\right)$ and resting $\mathrm{HR}\left(\mathrm{HR}_{\text {rest }}\right)$ $[7,10]:$

$$
\mathrm{HRR}=\mathrm{HR}_{\text {peak }}-\mathrm{HR}_{\text {rest }}
$$

$\% \mathrm{HRR}$ was calculated with the use of the following formula:

$$
\% \mathrm{HRR}=\left(\mathrm{HR}_{\mathrm{av}}-\mathrm{HR}_{\mathrm{rest}}\right) * 100 / \mathrm{HRR}
$$

\section{Statistical analysis}

All analyses were performed with the SPSS IBM Statistics 24 for Windows. Means and standard deviation $(S D)$ of the data were calculated. The Kolmogorov-Smirnov test served to check the distribution of the results. Results obtained among athletes from group A and group B were compared with $t$-test for independent samples. Statistical significance of the results was accepted at $p<0.05$. Additionally, Cohen's formula was used to calculate the effect size $(E S)$.
The following levels of effects were assumed: small: 0.2, medium: 0.5, and large: 0.8 [11].

\section{Ethical approval}

The research related to human use has complied with all the relevant national regulations and institutional policies, has followed the tenets of the Declaration of Helsinki, and has been approved by the local ethical committee.

\section{Informed consent}

Informed consent has been obtained from all individuals included in this study.

\section{Results}

The results of the HR parameters and the number of sprints for athletes representing group A (functional classification 1.0-2.5 points) and group B (functional classification $3.0-4.5$ points), and for total WB athletes are presented in Table 2 . There were significant differences and large ES between results achieved by group A and group B players in all parameters. Subjects representing higher functional abilities (group B) obtained higher results of $\mathrm{HR}_{\mathrm{av}}, \% \mathrm{HR}_{\mathrm{av}}, \mathrm{HR}_{\text {peak }}$, HRR, and \%HRR. $\mathrm{HR}_{\mathrm{av}}$ equalled 120.9 in group $\mathrm{A}$ and 136.2 in group $\mathrm{B}(p=0.001 ; E S=2.35) . \% \mathrm{HR}_{\mathrm{av}}$ value was 74.7 for group $\mathrm{B}$ and 67.2 for group $\mathrm{A}(p=$ $0.001 ; E S=1.64)$. A significantly higher $\mathrm{HR}_{\text {peak }}$ was achieved by athletes from group B as compared with those from group A (183.4 and 174.4, respectively; $p=0.001 ; E S=1.78$ ). HRR and \%HRR were higher for athletes from group B than those from group A (123.9 vs. 113.7 and 62.4 vs. 55.3 , respectively; $p=0.002$ and $E S=1.45$ for HRR; $p=0.004$ and $E S=1.40$ for $\%$ HRR). The analyses of \%HRR showed that athletes from group A worked with lower intensity in the $1^{\text {st }} \mathrm{HR}$ zone compared with athletes from group B, who worked in zone 2 (Table 2).

Athletes from the lower functional classes (functional classification 1.0-2.5 points, group A) sprinted more times during a WB game. An average number of sprints was 80.1 sprints per game for group A athletes and 53.2 for group B athletes ( $p=0.002 ; E S=1.42$ ) (Table 2).

Figure 1 shows characteristics of the work in different HR zones during WB matches. Athletes representing group A had the highest contribution in HR zone $2(25 \%)$ and the lowest in zone $5(15 \%)$. Athletes from group B worked with similar contributions in zones $2-5(20-22 \%)$ and with the lowest contribution in zone $1(15 \%)$. 


\section{HUMAN MOVEMENT}

J. Marszałek et al., Physiological response in wheelchair basketball game

Table 1. Physical impairment and anthropometric characteristic of the elite wheelchair basketball athletes

\begin{tabular}{rccclcc}
\hline Athlete & $\begin{array}{c}\text { Age } \\
\text { (years) }\end{array}$ & $\begin{array}{c}\text { Body mass } \\
(\mathrm{kg})\end{array}$ & $\begin{array}{c}\text { Body height } \\
(\mathrm{cm})\end{array}$ & \multicolumn{1}{c}{ Type of impairment } & $\begin{array}{c}\text { Functional } \\
\text { classification } \\
(1.0-4.5 \text { points })\end{array}$ & $\begin{array}{c}\text { Group } \\
(\mathrm{A}-\mathrm{B})\end{array}$ \\
\hline 1 & 27 & 77.1 & 185 & Paraplegia & 1.0 & $\mathrm{~A}$ \\
2 & 36 & 61.6 & 173 & Paraplegia & 1.0 & $\mathrm{~A}$ \\
3 & 33 & 75.6 & 185 & Paraplegia & 1.0 & $\mathrm{~A}$ \\
4 & 18 & 72.9 & 197 & Other & 4.5 & $\mathrm{~B}$ \\
5 & 33 & 76.3 & 183 & Amputation (single above knee) & 4.0 & $\mathrm{~B}$ \\
6 & 21 & 58.3 & 165 & Spina bifida & 3.0 & $\mathrm{~B}$ \\
7 & 40 & 78.0 & 196 & Paraplegia & 1.0 & $\mathrm{~A}$ \\
8 & 36 & 86.6 & 186 & Cerebral palsy & 3.5 & $\mathrm{~B}$ \\
9 & 21 & 75.0 & 170 & Spina bifida & 3.0 & $\mathrm{~B}$ \\
10 & 34 & 68.0 & 184 & Amputation (single above knee) & 4.0 & $\mathrm{~B}$ \\
11 & 44 & 92.6 & 190 & Amputation (single below knee) & 4.5 & $\mathrm{~B}$ \\
12 & 25 & 68.0 & 178 & Paraplegia & 1.5 & $\mathrm{~A}$ \\
13 & 28 & 71.0 & 190 & Paraplegia & 2.0 & $\mathrm{~A}$ \\
14 & 32 & 76.0 & 188 & Amputation (single above knee) & 4.0 & $\mathrm{~B}$ \\
15 & 34 & 69.0 & 178 & Paraplegia & 1.0 & $\mathrm{~A}$ \\
\hline
\end{tabular}

Group A

\begin{tabular}{llll}
$\bar{x} \pm S D$ & $30.4 \pm 5.4$ & $71.5 \pm 5.9$ & $183.6 \pm 7.9$ \\
\hline
\end{tabular}

\begin{tabular}{llll}
\hline Group B & & & \\
$\bar{x} \pm S D$ & $29.6 \pm 9.1$ & $75.7 \pm 10.5$ & $182.9 \pm 10.5$
\end{tabular}

$\bar{x} \pm S D \quad 29.6 \pm 9.1 \quad 75.7 \pm 10.5 \quad 182.9 \pm 10.5$

Total

$\bar{x} \pm S D \quad 30.0 \pm 7.4 \quad 73.7 \pm 8.7 \quad 183.2 \pm 9.1$

$\overline{\bar{x}}$ - mean, $S D$ - standard deviation

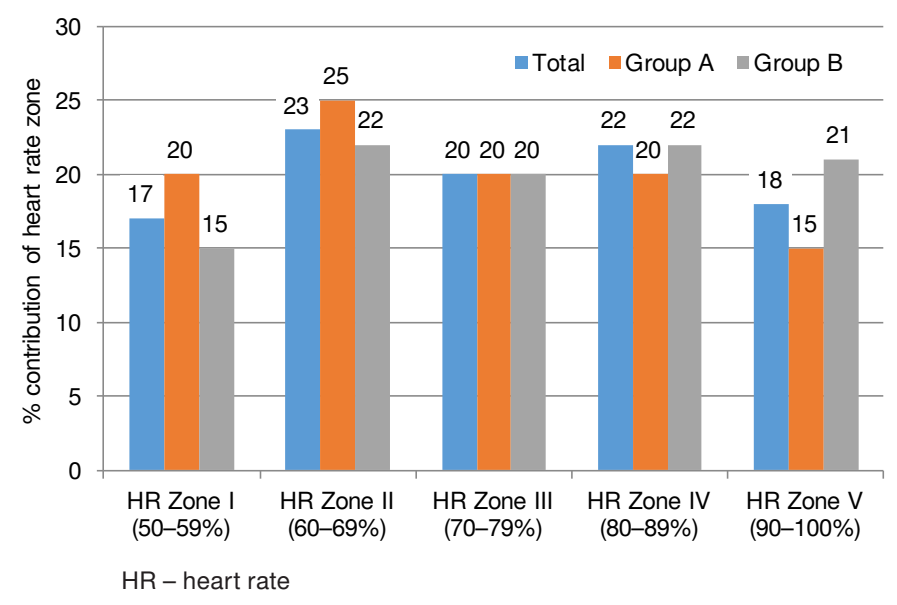

Figure 1. Athletes' physiological response during wheelchair basketball game - percentage contribution in 5 heart rate zones

Table 2. Heart rate parameters and the number of sprints among wheelchair basketball athletes representing group A and B during matches

\begin{tabular}{|c|c|c|c|c|c|c|c|c|}
\hline \multirow[t]{2}{*}{ Parameter } & \multicolumn{2}{|c|}{$\begin{array}{c}\text { Group A } \\
(1.0-2.5 \text { points })\end{array}$} & \multicolumn{2}{|c|}{$\begin{array}{c}\text { Group B } \\
\text { (3.0-4.5 points) }\end{array}$} & \multicolumn{2}{|c|}{ Total } & \multirow{2}{*}{$p$} & \multirow[t]{2}{*}{$E S$} \\
\hline & $\bar{x} \pm S D$ & $\min -\max$ & $\bar{x} \pm S D$ & $\min -\max$ & $\bar{x} \pm S D$ & $\min -\max$ & & \\
\hline $\mathrm{HR}_{\mathrm{av}}$ (beats/min) & $120.9 \pm 4.0$ & $115-127$ & $136.2 \pm 8.3$ & $121-149$ & $128.5 \pm 8.9$ & $115-149$ & 0.001 & 2.35 \\
\hline$\% \mathrm{HR}_{\mathrm{av}}(\%)$ & $67.2 \pm 3.3$ & $63-73$ & $74.7 \pm 5.4$ & $65-83$ & $70.1 \pm 5.4$ & $63-83$ & 0.001 & 1.64 \\
\hline $\mathrm{HR}_{\text {peak }}$ (beats/min) & $174.4 \pm 7.1$ & $160-183$ & $183.4 \pm 4.5$ & 177-192 & $178.8 \pm 6.5$ & 160-192 & 0.001 & 1.78 \\
\hline Sprints $(n)$ & $80.1 \pm 21.2$ & $55-120$ & $53.2 \pm 16.3$ & $33-80$ & $66.5 \pm 21.3$ & $33-120$ & 0.002 & 1.42 \\
\hline HRR (beats/min) & $113.7 \pm 7.5$ & $102-125$ & $123.9 \pm 4.9$ & $117-132$ & $119.2 \pm 6.8$ & $102-132$ & 0.002 & 1.45 \\
\hline \%HRR (\%) & $55.3 \pm 2.9$ & $51-60$ & $62.4 \pm 6.5$ & $52-73$ & $58.9 \pm 5.6$ & $51-73$ & 0.004 & 1.40 \\
\hline
\end{tabular}

$\bar{x}$ - mean, $S D$ - standard deviation, $\mathrm{HR}_{\mathrm{av}}$ - average heart rate, $\% \mathrm{HR}_{\mathrm{av}}$ - percentage of average heart rate,

$\mathrm{HR}_{\text {peak }}$ - maximum heart rate in a game, $\mathrm{HRR}$ - heart rate reserve, \%HRR - percentage of heart rate reserve 


\section{Discussion}

The aim of this study was to analyse the physiological response of $\mathrm{WB}$ athletes in game situations on the basis of HR zones and the number of sprints in relation to functional classification and disability. The physiological responses $\left(\mathrm{HR}_{\text {peak }}, \mathrm{HR}_{\mathrm{av}}, \% \mathrm{HR}_{\mathrm{av}}, \mathrm{HRR}\right.$, $\% \mathrm{HRR}$ ) which were analysed during WB games were significantly higher among athletes with higher functional classification (group B, athletes with 3.0-4.5 points). However, the comparison of the time spent by these players in each HR zone during a game revealed that they remained longer in lower level HR zones (I-II). The opposite situation was noticed for athletes with lower functional classification (group A, athletes with 1.0-2.5 points). This observation (the difference between A and B group athletes) constitutes evidence that the current classification system divides WB athletes appropriately in terms of their functional abilities and, in this case, different physiological responses during a game. That is why the authors of the study supposed that lower HR results could correlate with the type of impairment - all individuals from group A had a spinal cord injury. In a similar study, Iturricastillo et al. [12] observed values of absolute $\mathrm{HR}$ (current $\mathrm{HR}_{\text {peak }}$ ) and relative $\mathrm{HR}$ results in small-sided WB games among athletes with and without a spinal cord injury. They noticed that lower absolute HR was achieved by players with a spinal cord injury but no differences were found in relative HR results between the groups.

What is important to underline when discussing HR assessment before the match HR data analysis, in the current study, the valid aerobic test on an arm crank ergometer proposed by Molik et al. [9] was used to evaluate $\mathrm{HR}_{\text {peak }}$. Iturricastillo et al. $[12,13]$ assessed absolute HR in a field test - the 10-meter Yo-Yo intermittent recovery test level 1 (YYIR1). Iturricastillo et al. [13] and Molik et al. [9] used valid and reliable but different $\mathrm{HR}_{\text {peak }}$ assessment methods. In consequence, we decided to use the latter approach in our study.

Also, Pérez et al. [7] completed research exploring the physiological response in WB. They underlined that the higher the players' functional potential, the higher the \%HRR attained. Moreover, they concluded that physiological demands in a team sport competition and in adapted sports such as WB should be related to HR and \%HRR of the athletes, personal characteristics like age, weight, gender, and especially to the players' functional classification. It would be helpful to find the perceived exertion of players with and without a spinal cord injury to be more subjective and detailed in future analyses [13].
On the other hand, West and Krassioukov [14] found a different relationship. They analysed autonomic cardiovascular function of $14 \mathrm{WB}$ players in relation to the WB classification system. Their study showed that the current sports classification system used in WB does not accurately reflect cardiovascular function and thus places some athletes at a distinct disadvantage/advantage within their respective sports class (there are not clear differences in cardiovascular function between athletes from different sports class in WB). The current analysis implies that further investigation is needed to describe the relationship between the physiological response during WB matches and athletes' functional classification. There is a need to continue this course of study.

In the present paper, $\mathrm{HR}_{\mathrm{av}}$ values for both groups were relatively low (128.5 beats/min). Pérez et al. [7] noted similar results for Spanish elite athletes (132.1 beats/min). However, Croft et al. [15] showed $\mathrm{HR}_{\mathrm{av}}$ value of 163 beats/min calculated for a whole WB game and $\mathrm{HR}_{\mathrm{av}}$ of 154 beats/min during basketball active playing time (without breaks and stops). Also, dos Santos et al. [16] observed $\mathrm{HR}_{\mathrm{av}}$ values equal 163 beats/min for two basketball athletes. In the current study, all HR parameters were monitored during an entire game (with breaks between quarters, etc.) [16]. That is why physiological profiles were different compared with other studies.

Our analysis confirmed previous investigations by Pérez et al. [7]. We noted the \%HRR value of 58.9 while Pérez et al. showed 58.4. These authors also observed higher all HR values for players with higher functional classifications compared with those with lower functional classifications.

The number of sprints performed by WB athletes in a game was another factor considered in this study. The results showed that subjects with lower functional classification (group A) did significantly more sprints in a game than those with higher functional classification (group B). We argue that the difference is due to the fact that players with 1.0-2.5 points had a different tactical role than athletes with 3.0-4.5 points. They tend to mark opponents more closely (stop in front of the opponent) and play more of a defensive than an offensive role. They stop the wheelchair more often, e.g. when shooting and when manoeuvring the wheelchair between other players. When group A players want to start moving, they have to push the wheelchair very dynamically and quickly (their acceleration is higher). Group B players typically move most of the time during the match, and they do not need to push the wheelchair so dynamically to start 
the movement because their trunk control is significantly better and they are apt not stop in a shooting action. They manoeuver the wheelchair faster between opponents and they maintain the speed of their wheelchair. That is why athletes with lower functional classification did significantly more sprints in this study than those with higher functional classification.

In the current study, differences in \%HRR between the athletes were observed. The value was higher among subjects from group B, who played with higher intensity in the analysed matches compared with players with a spinal cord injury, i.e. group A (\%HHR was 62.4 vs. 55.3, respectively). Moreover, all analyses of HR zones confirmed that athletes from group A spent the least amount of time in the $5^{\text {th }}$ zone (HR zone V: 90 $100 \%$ ), and those from group B worked the least amount of time in the $1^{\text {st }}$ zone (HR zone I: 50-59\%). We perceived that lower values of all HR results were achieved in this study compared with the research by Croft et al. [15] and dos Santos et al. [16] because time-outs and all breaks were considered in the current study calculations. Perhaps, considering only the active part of the game would indicate a higher level of the athletes' intensity.

Study limitation and recommendation

for future research

In this study, active time and inactive time during a match were included. In future studies, athletes' active time of play should be compared with the total time (active and inactive). Half-time and quarter intermissions, time-outs in each match, etc. should be cut from the main analysis. The physiological response should be also compared with each athlete's functional class, not only between two groups. Future analyses should consider the match score (winning or losing) and the order of games (the final game vs. the first game), as well as athletes' perceived exertion, as other authors advise [13]. It would be interesting to measure the average distance which athletes travel during a match.

\section{Conclusions}

The current study confirmed the differential specificity of a WB game, i.e. all players were found in all $5 \mathrm{HR}$ zones with different contribution (from $50 \%$ to $100 \%$ of $\mathrm{HR}_{\text {peak }}$, where $50 \%$ of $\mathrm{HR}_{\text {peak }}$ is close to $\left.\mathrm{HR}_{\text {rest }}\right)$. It was observed that there are significant differences in the physiological response (all HR parameters) between WB athletes representing different functional levels. This knowledge is needed to plan the system of preseason conditioning exercises for each WB athlete. Further research is needed in this field to better understand the physiological response of WB athletes during games.

\section{Acknowledgments}

The authors would like to thank the players and coaches from the Polish National Wheelchair Basketball Team for their participation in the study. The study has been supported by a grant within the Academic Sport Research from the Polish Ministry of Higher Education and Science (PB-87; N RSA4 01854).

\section{Disclosure statement}

No author has any financial interest or received any financial benefit from this research.

\section{Conflict of interest}

The authors state no conflict of interest.

\section{References}

1. Pezdek K. Considering values in the sport experiences of wheelchair basketball players. Hum Mov. 2018;19(1): 10-19; doi: 10.5114/hm.2018.73607.

2. International Wheelchair Basketball Federation. Official player classification manual. Winnipeg: IWBF; 2014.

3. International Wheelchair Basketball Federation. Official wheelchair basketball rules. Mies: IWBF; 2014.

4. Paulson T, Goosey-Tolfrey V. Current perspectives on profiling and enhancing wheelchair court sport performance. Int J Sports Physiol Perform. 2017;12(3): 275-286; doi: 10.1123/ijspp.2016-0231.

5. Coutts KD. Dynamics of wheelchair basketball. Med Sci Sports Exerc. 1992;24(2):231-234; doi: 10.1249/ 00005768-199202000-00012.

6. Pérez J, Rabadán M, Sampedro J. Wheelchair basketball competition exigency profile: heart rate evaluation concerning specific team sport variables. Electronic Proceedings of the VISTA 2003 Conference. Bollnäs, Sweden: Swedish Development Center for Disability Sport; 2003.

7. Pérez J, Rabadán M, Pacheco JL, Sampedro J. Heart rate assessment during wheelchair basketball competition: its relationship with functional classification and specific training design. In: Higgs C, Vanlandewijck YC (eds.). Sport for persons with a disability. Berlin: ICSSPE - IPC; 2007; 151-174.

8. Iturricastillo A, Yanci J, Barrenetxea I, Granados C. Game intensity analysis of wheelchair basketball players during play-off matches [in Spanish]. Retos. 2016;30: 54-58.

9. Molik B, Kosmol A, Morgulec-Adamowicz N, LencseMucha J, Mróz A, Gryko K, et al. Comparison of aerobic 
performance testing protocols in elite male wheelchair basketball players. J Hum Kinet. 2017;60:243-254; doi: 10.1515/hukin-2017-0140.

10. Janssen TW, van Oers CA, van der Woude LH, Hollander AP. Physical strain in daily life of wheelchair users with spinal cord injuries. Med Sci Sports Exerc. 1994;26(6):661-670; doi: 10.1249/00005768-199406 000-00002.

11. Cohen J. Statistical power analysis for the behavioral sciences. New York: Lawrence Erlbaum Associates; 1988.

12. Iturricastillo A, Yanci J, Los Arcos A, Granados C. Physiological responses between players with and without spinal cord injury in wheelchair basketball small-sided games. Spinal Cord. 2016;54(12):11521157; doi: 10.1038/sc.2016.43.

13. Iturricastillo A, Yanci J, Granados C, Goosey-Tolfrey V. Quantifying wheelchair basketball match load: a comparison of heart rate and perceived exertion methods. Int J Sports Physiol Perform. 2016;11(4):508-514; doi: 10.1123/ijspp.2015-0257.

14. West CR, Krassioukov AV. Autonomic cardiovascular control and sports classification in Paralympic athletes with spinal cord injury. Disabil Rehabil. 2017;39(2): 127-134; doi: 10.3109/09638288.2015.1118161.

15. Croft L, Dybrus S, Lenton J, Goosey-Tolfrey V. A comparison of the physiological demands of wheelchair basketball and wheelchair tennis. Int J Sports Physiol Perform. 2010;5(3):301-315; doi: 10.1123/ijspp.5.3. 301.

16. Dos Santos PP, de Souza GC, Alves DL, Rodacki ALF, Lima-Silva AE, De-Oliveira FR. Physiological demands of wheelchair basketball. J Exerc Physiol Online. 2017; 20(5):52-59. 